\title{
A dark colour form of Cordulegaster heros (Odonata: Cordulegastridae)
}

Otakar Holuša

A dark colour form of Cordulegaster heros (Odonata: Cordulegastridae).- Čas. Slez. Muz. Opava (A), 60: 235-237, 2011.

Abstract: In July 2010 a dark colour form of the male of Cordulegaster heros was recorded at the Kamenný potok stream in the village of Modra-Piesok in the southern part of the Malé Karpaty Mts. in Slovakia. Differences between the typical colouring and the dark colour form are described.

Keywords: Odonata, Cordulegaster heros, dark colour form of male, description of colouring

\section{Introduction}

Cordulegaster heros was described by Theischinger (1979), with the type material from Niederösterreich (Andrä vor dem Hagnethal) in central Europe. This species is the largest dragonfly in Europe, females having a wingspan up to $115 \mathrm{~mm}$ and a body length up to 89 $\mathrm{mm}$. C. heros occurs in part of the eastern Mediterranean (the Balkan Peninsula - including Greece, Macedonia, Montenegro, Albania, Croatia, Slovenia, Bulgaria, eastern Italy and Romania) and up into central Europe (the foothills of the Alps in eastern Austria and the foothills of the Carpathians Mts.) (Boudot 2001, Van Pelt 2006). In Austria the species occurs in southwestern Waldviertel (Melk district), where it is at the northwestern border of its range (Raab et al. 2006, Schweighofer 2008). Its northernmost occurrence is in Slovakia in the Malé Karpaty Mts., in the Borská nížina lowland in the western part of Slovakia (Blaškovič et al. 2003, Janský \& David 2008, Holuša \& Kúdela 2010) and in central Slovakia near Revúca town (Holuša \& Kúdela 2010). The species has also been found in the Czech Republic (Staufer \& Holuša 2010) with confirmation of a permanent population there (Holuša et al. 2011). The species habitats are small meandering streams in cultural landscape or in forest complexes.

Theischinger (1979) described the body colour. Each species of the genus Cordulegaster has a typical combination of black with yellow stripes on the thorax and abdomen. Typical of the boltoni-group is a thin yellow stripe along the ventro-posterior edge of the first abdominal segment. So far, no variations have been described in the colouration of Cordulegaster heros.

The aim of this paper is to place on record a completely different - dark coloured male of Cordulegaster heros.

\section{Material and results}

On $11^{\text {th }}$ July 201040 males and 5 females were found at the Kamenný potok stream, Modra-Piesok village, in the southern part of the Male Karpaty Mts $\left(48^{\circ} 22^{\prime} 17^{\prime}\right.$ ' $\mathrm{N}, 17^{\circ} 17^{\prime} 59^{\prime}$ ' $\mathrm{E}, 332 \mathrm{~m}$ a.s.l) in the region of Western Slovakia. Included was one male of Cordulegaster heros with atypical dark colouring (see Fig. 1). This specimen is stored in the collection of O. Holuša.

The typical coloration of Cordulegaster heros is described by Theischinger (1979); a similar description is given by Askew (1988). The basic colour of the whole body is black. On the thorax thre are conspicuous broad yellow stripes on both epimerons, i.e on the mesosternum and metasternum.

There is a large triangular yellow spot on the mesospisternum and a narrow yellow stripe on the dorsal surface of the metaepisternum. There is a wider transverse stripe in the middle section of abdominal segments S2-S8. These stripes are not interrupted in the dorsal region. A thin yellow stripe is located on the dorsal part of the posterior edge of S2 and S3. These stripes are interrupted in the dorsal region. The posterior lower part of the first tergite has a yellow semicircular mark (characteristic of the boltoni-group). Also, on the ventral surface of $\mathrm{S} 2$ is a yellow stripe. The S2 in the surroundings of auricula has a larger yellow spot that touches the anterior ventral edge of S2. The S3 medium yellow stripe in the lateral area of S3 extends towards S2 (Fig. 2). Yellow stripes on the tergites of S4-S7 are larger in the ventral part of tergites. Females have a similar abdominal colouration but the stripes are much broader than in males. 
In the dark colour form abdominal segments S1-S4 are conspicuously different (Fig. 1). A small reduction of the yellow strip is at the top of metaepisternum.

$\mathrm{S} 1$ - the tergite of this segment is entirely black.

S2 - all the yellow spots are reduced significantly, the median dorsal stripe is reduced to two small yellow spots with a blurred edge; also the rear dorsal stripe is reduced to a very small spot. A spot near the ventral posterior edge of tergite is reduced to a small round speck, while a spot in the auricula region is reduced and does not reach the edges of tergite.

S3 - all the spots are reduced in size, the main dorsal stripe is reduced is imperceptible, the tergite appearing black. The posterior dorsal stripe is in the form of small spots. The lateral spot at the bottom of the contact with $\mathrm{S} 2$ is reduced and is almost imperceptible with an ochre colour.

$\mathrm{S} 4$ - the main stripe in the dorsal region of the segment has a rear edge that is indistinct and blurred. There is no yellow spot at the bottom of the tergite.

S5-S8 - the main yellow streaks on the dorsal regions of these segments are blurred at their edges. In each segment the yellow spot in the lateral and ventral region is completely reduced and the ventral regions are brown;

Any morphological deviations in particular abdominal appendages were not identified in this specimen.

\section{Discussion}

Species of the genus Cordulegaster do not show large variability of colouration. In the author's surveys of the population of Cordulegaster heros in the Slovak Republic (Holuša \& Kúdela 2010) and in other areas within its range (Holuša nepubl.) no significant colour forms were observed. Nor do any published works contain any description of the variability of the spots on the thorax or abdomen (Theischinger 1979, Askew 1988). Some variability is observed only on some small spots, especially by the stripe on metaepisternum, at the abdomen by a thin strip at the back of the S2. Very interesting is the total black coloration of $\mathrm{S} 1$ i.e. absence of yellow colouration, because the shape of yellow coloration on S1 is a basic sign for the determination of groups of Cordulegaster-species. Therefore this is probably just a completely unique case.

Acknowledgements. This paper was worked up in the frame of the research project „Strategy of the management of territories with a special protection status“ MSM 6215648902-04 of Faculty Forestry and Wood Technology of Mendel University in Brno.

\section{References}

Askew R. R. (1988): The Dragonflies of Europe. 291 pp. Harley Books, Colchester.

Blaškovič T., Bulánková E. \& Šíbl J. (2003): First record of Cordulegaster heros ssp. heros Theischinger, 1979 (Cordulegastridae, Odonata) from Slovakia. - Biologia (Bratislava), 58 (2): 293-294.

Boudot J.-P. (2001): Les Cordulegaster du Paléarctique occidental: identification et répartition (Odonata, Anisoptera, Cordulegastridae). - Martinia, 17: 1-34.

Holuša O., Dalecký V. \& Holušová K. (2011) : First record of larvae of Cordulegaster heros (Odonata: Cordulegastridae) in the Czech Republic. - Acta Musei Beskidensis, 3: 65-69.

Holuša O. \& Kúdela M. (2010): New records of occurrence of Cordulegaster heros Theischinger, 1979 in Slovakia. - Acta Musei Beskidensis, 2: 75-87.

Janský V. \& David S. (2008): Výskyt vážky Cordulegaster heros ssp. heros (Odonata: Cordulegastridae) na Slovensku. - Acta Rerum Naturalium Musei Nationalis Slovakiae, 54: 61-68.

Raab R., Chovanec A. \& Pennerstorfer J. (2006): Libellen Österreichs. 345 pp. Springer, Wien.

Schweighofer W. (2008): Syntopes Vorkommen von Cordulegaster boltonii und C. heros an einem Bach im westlichen Niederösterreich (Odonata: Cordulegastridae). - Libellula, 27(1/2): 1-32.

Staufer M. \& Holuša O. (2010): First record of Cordulegaster heros in the Czech Republic, with notes on Cordulegaster spp. in southern Moravia (Odonata: Cordulegastridae). - Libellula, 29 (3/4): 197-204.

Theischinger G. (1979): Cordulegaster heros sp. nov. und Codulegaster heros pelionensis ssp. nov., zwei neue Taxa des Cordulegaster boltoni (Donovan) - Komplexes aus Europa (Anisoptera: Cordulegasteridae). - Odonatologica, 8 (1): 23-38.

Van Pelt G. J. (2006): Cordulegaster Leach, 1815 - Goldenrings. pp. 210-221. In: Dijkstra K-D.B. \& R. Lewington: Field guide to the dragonflies of Britain and Europe including western Turkey and northwestern Africa. British Wildlife Publishing, Gillingham. 


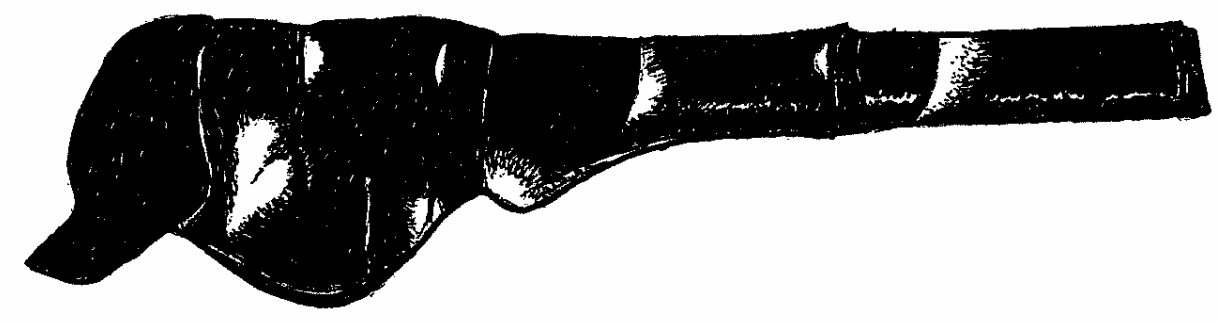

Fig. 1: Lateral view of the anterior part of the abdomen (segments S1 - S4) of the dark colour form of the male of Cordulegaster heros, which was found on $11^{\text {th }}$ July 2010 at the Kamenný potok stream in the locality of Modra-Piesok village in the Malé Karpaty Mts., Slovakia.

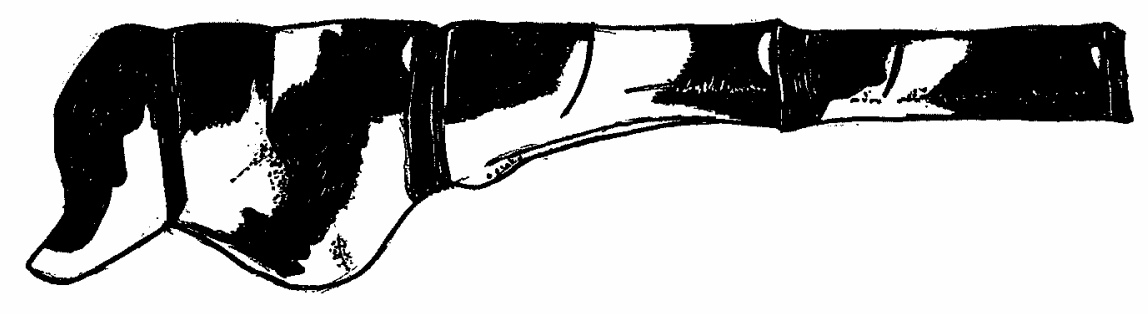

Fig. 2: Lateral view of the anterior part of the abdomen (segments S1 - S4) of the typical colour form of the male of Cordulegaster heros (specimen from a population at the Kamenný potok stream in the locality of Modra-Piesok village in the Malé Karpaty Mts., Slovakia).

Author's address: Otakar Holuša, Dept. of Forest Protection and Wildlife Management, Faculty of Forestry and Wood Technology, Mendel University in Brno, Zemědělská 3, CZ-613 00 Brno; e-mail: holusao@email.cz 